\title{
Implanon Discontinuation Rate and Associated Factors among Women who ever Used Implanon in the Last Three Years in Debre Markos Town, Northwest Ethiopia, 2016, Cross Sectional Study
}

\author{
Melese Siyoum ${ }^{1}$, Zerfu Mulaw ${ }^{2}$, Mulunesh Abuhay ${ }^{3}$ and Habtamu Kebebe ${ }^{4}$ \\ ${ }^{1}$ College of Medicine and Health Sciences, P.O.Box 1560, Hawassa University, Hawassa, Ethiopia \\ ${ }^{2}$ Midwifery department, College of Medicine and Health Sciences, University of Gondar, Ethiopia \\ ${ }^{3}$ Midwifery department, College of Medicine and Health Sciences, University of Gondar, Ethiopia \\ ${ }^{4}$ Midwifery department, College of Medicine and Health Sciences, Wollega University, Ethiopia
}

\begin{abstract}
:
Introduction: Contraceptive discontinuations contribute substantially to the total fertility rate, unwanted pregnancies and induced abortions.In developing countries, contraceptive discontinuation rate is very common. While the Ethiopian government emphasizes onthe provision of long-acting contraceptive methods, women who start to use the method were discontinuing it and the rate of discontinuation is understudied.

Objective: To assess Implanon discontinuation rate and associated factors among women who ever used Implanon from January 09/2013 to October 11/2015 in Debre Markos town, northwest Ethiopia: 2016.

Methodology: The community based cross-sectional study was conducted from January 10 to February 10/2016 through face to face interview. A total of 348 women were selected by simple random sampling technique. Epidata version 3.1 and statistical software package for social science (SPSS) version 20 were used for data entry and analysis respectively. Factors associated with Implanon discontinuations were analyzed using binary and multivariable logistic regression, $p$-value $<0.05$ were considered statistically significant.

Result: The overall discontinuation rate in the last three years was $46.5 \%$ with a rate of 10.5\%, 23.9\%, 38.2\% and $46.5 \%$ at 6, 12, 24 and 36 months respectively. Attending college and above level education $(A O R=2.2, C I$ $(1.16,4.16)$, no history of pregnancy $(A O R=3.06, C I=(1.63-5.76))$, lack of pre-insertion counseling $(A O R=$ $1.2, C I=(1.02,3.89))$, perceived not satisfied with service provided $(A O R=4.86, C I=(2.66,8.91))$ and experience of side effect $(A O R=3.14, C I=(1.7,5.54))$ were significantly associated with Implanon discontinuation.
\end{abstract}

Conclusion and Recommendation: The discontinuation rate of Implanon in this study was high. Quality family planning service is essential to reduce discontinuation rate.

Keywords: Implanon, Discontinuation, progestin-only, Implant, Ethiopia

\section{BACKGROUND}

Implanon is one of the long-term and reversible sub-dermal contraceptive implants. It is a single rod, containing $68 \mathrm{mg}$ of Etonogestrel to offer contraception for three years[1]. Contraceptive discontinuations contribute substantially to the total fertility rate, unwanted pregnancies, and induced abortions [2,3]. An estimated $13 \%$ of maternal mortality from unsafe abortion is due to unintended pregnancy [4]. Contraceptive discontinuation in developing countries in the first year of use is common (18-63\%), and that the majority of these discontinuations are among women who are still in need of contraception[5].

Even though Implanon is believed to be safe and effective, its discontinuation rate even in the developed country reaches up to $50 \%$ before three yearsof insertion[6]. Besidesits low utilization, the discontinuation rate is common in African countries [7], due to different reasons. Changes in 
menstrual bleeding patterns were the common reasons for discontinuation described in various works of literatures $[8,9]$. Other reasons mentioned for the discontinuation of the Implanon includesmood swings, headaches and weight gain [10].

In Ethiopia, contraceptive prevalence rate is $29 \%$ for all women and $42 \%$ for currently married women, where the implants account only 5\%[11] and many of the women have negative attitude about long-acting contraceptives [12]. To address these problems, the EthiopianFederal Ministry of Health (FMoH) developed a plan to expand contraceptive method mix by providing Implanon at community level since2009 [13-15] in collaboration with generous donors support, nongovernmental organizations and public-private partnerships.Despite these all effort,still there is low utilization in general,and even those who have started to use the method are discontinuing it. The discontinuation rate and factors associated with discontinuation are understudied in Ethiopia as previous studies were done to assess early discontinuation rate in the first two yearsonly. The result of those studies showed high discontinuation rate in Ethiopia [16] but there is no published data from this specific study area. Thus, this studywas aimed to assess the rate of discontinuation and associated factors among women who ever used Implanon in the last three years in Debre Markos town, Northwest Ethiopia.

\section{Methodology}

\section{Study Setting and Populations}

Community-based cross sectional study was conductedin Debre Markos town, Northwest Ethiopia, from January to February 2016. Among 4867 Women for whom Implanon was inserted in the last three years, since January 09/2013 to October 11/2015 in Debre Markos town, 348 participants were selected. Simple random sampling technique was used to select study participants, and 264 women who took Implanon in the last three months prior to study period were excluded as at least onereference evaluation period of 90 days is required to assess bleeding patterns.

\section{Data Collection Tools and Procedures}

Data was collected through face to face interview usingstructured questionnaire adapted from related literatures. The questionnaire was first prepared in English and translated to Amharic version (local language) and then translated back to English by reproductive health professionals to keep its consistency. Data was collected by seven urban Health Extension Workers from their respective working kebeles.

\section{Data Processing}

After collected data was cleaned, coded and entered into Epi data version 3.1 and exported to SPSS version 20 software packages for analysis. Frequencies for all variables were run to identify missing values. Continuous data were checked for their normal distributionand coded. Cross-tabulation was done to determine variables with frequency of less than five. Variables with very few frequencies were recorded. Mean, median, standard deviation, proportionsand rate were calculated for descriptive data and the results presented intables, graphs and charts. Factors associated with Implanon discontinuation were firstanalyzed using binary logistic regression and variables with the p-value $\leq$ 0.2 were analyzed in multivariable logistic regression to check their effectson the outcome variable. In multivariatelogistic regression, associations were analyzed at the confidence level of $95 \%$ with their respective odds ratioandthe $\mathrm{p}$-value of $<0.05$ was considered statistically significant.

\section{RESULTS}

\section{Socio-Demographic Characters}

A total of 314 participants responded to the questionnaires making a response rate of $90.23 \%$ while $14(4.02 \%)$ individuals werenot volunteer to participate and 20(5.75\%) were not present in the study area. The age of the participants was between 18 and 45 years with the mean $( \pm$ SD) age of $27.97 \pm$ 5.45 years. Majority of the participants 263(83.8\%) were married, 297(94.6\%) were Orthodox, 308 (98.7\%) were Amhara by ethnicity, 93 (29.6\%) were homeworker and 124(39.5\%) have no formal Education. The average monthly income ranges from 00.00 (no steadyincome) to 9900 ETB with a median of 1600.00 ETB. 
Implanon Discontinuation Rate and Associated Factors among Women who ever Used Implanon in the Last Three Years in Debre Markos Town, Northwest Ethiopia, 2016, Cross Sectional Study

\section{Reproductive and Past Contraceptive History}

Majority 230(73.2\%) of the participants hada history of pregnancy at least once before they used Implanon. Among them, 217 (94.3\%) had at least one alive child and 44(19.1\%) had abortion history. The majority of the participants 244(77.7\%) have a desire to be pregnant in the future. More than half of the participants, 205(65.3\%) have used other contraceptives before taking Implanon. Among them, 143(69.8\%) used injectable, 60 (29.3\%) used pills and two participants had used Jadelle.

Table 1: Socio-demographic Status of women who ever used Implanon in the last three years in Debra Markos town (N=314), northwest Ethiopia, 2016.

\begin{tabular}{|c|c|c|c|}
\hline & & Number & Percent \\
\hline \multirow[t]{4}{*}{ Participant's Age } & $<21$ & 37 & 11.8 \\
\hline & $21-25$ & 76 & 24.2 \\
\hline & $26-30$ & 112 & 35.7 \\
\hline & $31-34$ & 54 & 17.2 \\
\hline \multirow{4}{*}{ Women's Ethnicity } & $>35$ & 35 & 11.1 \\
\hline & Amhara & 308 & 98.1 \\
\hline & Oromo & 4 & 1.3 \\
\hline & Tigre & 2 & 0.6 \\
\hline \multirow[t]{3}{*}{ Women's Religion } & Orthodox & 297 & 94.6 \\
\hline & Muslim & 13 & 4.1 \\
\hline & protestant & 4 & 1.3 \\
\hline \multirow{3}{*}{ Marital status } & single & 39 & 12.4 \\
\hline & Married & 263 & 83.8 \\
\hline & divorced & 12 & 3.8 \\
\hline \multirow[t]{6}{*}{ Occupation } & Gov't Employee & 70 & 22.3 \\
\hline & Merchant & 46 & 14.6 \\
\hline & Homeworkers & 93 & 29.5 \\
\hline & Private Employee & 27 & 8.6 \\
\hline & Daily laborer & 51 & 16.2 \\
\hline & Others(farmer, student) & 27 & 8.6 \\
\hline \multirow{4}{*}{$\begin{array}{ll}\text { Average monthly } \\
\text { Income }\end{array}$} & $<750$ & 79 & 25.2 \\
\hline & $751-1600$ & 79 & 25.2 \\
\hline & $1601-3000$ & 101 & 32.2 \\
\hline & $>3000$ & 55 & 17.5 \\
\hline \multirow{5}{*}{$\begin{array}{lll}\begin{array}{l}\text { Women's } \\
\text { education }\end{array} & \text { level } & \text { of } \\
\end{array}$} & & & \\
\hline & Noformal education & 124 & 39.5 \\
\hline & Primary school & 43 & 13.7 \\
\hline & Secondary school & 54 & 17.2 \\
\hline & College and above & 93 & 29.6 \\
\hline
\end{tabular}

\section{Pre-Insertion Counseling Service during Implanon Provision}

Most of the participants, 248 (79\%) got counseling service during Implanon provision with 213 $(85.9 \%)$ individual and 35(14.1\%) mass counseling. Among those who got counseling service, $219(88.3 \%)$ were counseled on the advantage of the method. However, 113 (45.6\%) were not counseled on possible side effects of Implanon. Half of the participants 155(49.4\%) had chosen the method by themselves but for 73 (23.2\%) users Implanon was selected by service providers. The most common reason for choosing the method at the beginning was its cost-effectiveness in terms of its duration of protection. More than half of the participants $170(54.1 \%)$ took the method from health center (Table2). In this study, none of the participants were appointed for check-up and of all users $97(30.9 \%)$ reported that they were not satisfied with the service provision during Implanon insertion. 
Melese Siyoum et al.

Table 2: Pre-insertion counseling service for women who ever used Implanon in the last three years in Debre Markos town (n=314), northwest Ethiopia, 2016

\begin{tabular}{|c|c|c|c|}
\hline Character & & Number & Percent \\
\hline \multirow[t]{2}{*}{ Got counseling service $(n=314)$} & Yes & 248 & 79 \\
\hline & No & 66 & 21 \\
\hline \multirow[t]{2}{*}{ Type of counseling $(n=248)$} & Individual & 213 & 85.9 \\
\hline & Mass counseling & 35 & 14.1 \\
\hline \multirow[t]{4}{*}{ Topics discussed during counseling $(\mathrm{n}=248)$} & Advantage & 219 & 88.3 \\
\hline & Duration of action & 190 & 76.6 \\
\hline & Effectiveness & 131 & 52.8 \\
\hline & Side effect & 135 & 54.4 \\
\hline \multirow[t]{3}{*}{ Possible side effects counseled $(n=135)$} & Bleeding disorder & 107 & 79.3 \\
\hline & Headache & 78 & 57.8 \\
\hline & Weight gain & 44 & 32.6 \\
\hline \multirow[t]{4}{*}{ Main decider to use the method } & Myself & 155 & 49.4 \\
\hline & My husband & 12 & 3.8 \\
\hline & Method provider & 73 & 23.2 \\
\hline & Discussion with husband & 74 & 23.6 \\
\hline \multirow[t]{3}{*}{ Reason for choosing the method } & Duration of action & 226 & 72 \\
\hline & No side effect & 42 & 13.4 \\
\hline & Effective & 46 & 14.6 \\
\hline \multirow[t]{3}{*}{ Perceived Satisfied with service provided } & Yes & 217 & 69.1 \\
\hline & No & 97 & 30.9 \\
\hline & Health Center & 170 & 54.1 \\
\hline \multirow[t]{4}{*}{ Implanon providing site } & Hospital & 52 & 16.6 \\
\hline & Marie stops & 41 & 13.1 \\
\hline & FGAE & 46 & 14.6 \\
\hline & Private clinics & 5 & 1.6 \\
\hline
\end{tabular}

\section{Rate and Reasons for Implanon Discontinuation}

The overall discontinuation rate of Implanon in the last three years wasobserved in 146(46.5\%) of participants.The discontinuation of Implanon starts as early as two weeks and as long as 35 months. The median duration of use was12 months with the first, second and third interquartile range of 7, 12 and 24 moths respectively (Table3).Among the discontinuers, 33(22.6\%) discontinued within 6months, $75(51.4 \%)$ within 12 monthsand $120(82.2 \%)$ within 24 months.

Table 3: Implanon discontinuation rate among women who ever used Implanon in the last three years in Debre Markos town (n=314), northwest Ethiopia; 2016

\begin{tabular}{|c|c|c|}
\hline Duration of use & Frequency & Percent \\
\hline$<6$ months & 33 & 10.5 \\
\hline$<12$ months & 75 & 23.9 \\
\hline$<24$ months & 120 & 38.2 \\
\hline$<35$ months & 146 & 46.5 \\
\hline Not discontinued & 168 & 53.5 \\
\hline Total & 314 & 100 \\
\hline
\end{tabular}

Two third of the participants, $211(67.2 \%)$, had faced side effect of the method. Among them $128(60.7 \%)$ faced menstrual disturbance, $76(36 \%)$ faced headache, $40(19 \%)$ weight gain, 61(28.9\%) arm pain and 12(5.7\%) faced mood change. Among those who faced menstrual disturbances, 25(19.5\%) faced heavy bleeding, 66(51.6\%) prolonged bleeding, 18(14.1\%) amenorrhea and 19(14.8\%) faced spotting. The most commonly reported reasons for discontinuation were the presence 
Implanon Discontinuation Rate and Associated Factors among Women who ever Used Implanon in the Last Three Years in Debre Markos Town, Northwest Ethiopia, 2016, Cross Sectional Study

of side effects $89(61 \%)$ and need to be pregnant $44(30.1 \%)$. The most commonly reported side effects causing Implanon discontinuations were menstrual disturbance 52(58.43\%), Arm pain 23 (25.84\%), weight gain $9 \%$ and headache $6.74 \%$. In this study, nine participants out of 12 who developed mood change had already discontinued the method. Among participants who did not discontinue the method (168) during the study period, 31(18.5\%) decided to discontinue it before completion of three years.

\section{Factors Associated with Implanon Discontinuation}

Variables like women's ethnicity, religion, knowledge of contraceptives, Implanon providing site, an appointment for check-up and mood change were excluded from analysis for association due to low frequencies in one category when checked by cross tabulation. All other socio-demographic characters, reproductive and obstetric factors, counseling service and experience of side effect were checked individually for the presence of association in binary logistic regression. Hence, women's age, the level of education, history of pregnancy, pre-insertion counseling service, perceived satisfaction with the service provided, main decision makerto use Implanon, the reason for preferring method at beginning and experience of side effect were associated with Implanon discontinuation at $\mathrm{p}$-value $\leq 0.2$. However, in multivariate logistic regression, attending college and above level education $(\mathrm{AOR}=2.2,95 \% \mathrm{CI}=(1.16-4.16)$, no history of pregnancy $[\mathrm{AOR}=3.06,95 \% \mathrm{CI}=(1.63$, $76]$, no pre-insertion counseling service $[\mathrm{AOR}=1.2,95 \% \mathrm{CI}=(1.02,3.89)]$, perceived not satisfied with service provided $[\mathrm{AOR}=4.86,95 \% \mathrm{CI}=(2.66,8.91)]$ and experience of side effect $[\mathrm{AOR}=3.14$, $95 \% \mathrm{CI}=(1.7,5.54)]$ were significantly associated with Implanon discontinuation (Table4).

Table 4: Factors Associated with Discontinuation of Implanon among women who ever used Implanon in the last three years in Debre Markos town, northwest Ethiopia, 2016

\begin{tabular}{|c|c|c|c|c|c|c|}
\hline \multirow[t]{2}{*}{ Variable } & & \multicolumn{2}{|c|}{$\begin{array}{l}\text { Implanon } \\
\text { iscontinued }\end{array}$} & \multirow[t]{2}{*}{$\begin{array}{l}\text { Crude OR } \\
(95 \% \text { CI })\end{array}$} & \multirow[t]{2}{*}{$\begin{array}{l}\text { Adjusted OR } \\
(95 \% \mathrm{CI})\end{array}$} & \multirow[t]{2}{*}{ P-value } \\
\hline & & Yes & No & & & \\
\hline & $>35$ & 19 & 16 & $0.57(0.22-1.48)$ & & \\
\hline \multirow{4}{*}{$\begin{array}{l}\text { Women's } \\
\text { Age }\end{array}$} & \multirow{4}{*}{$\begin{array}{l}31-35 \\
26-30 \\
21-25 \\
<21\end{array}$} & \multirow{4}{*}{$\begin{array}{l}14 \\
45 \\
41 \\
25\end{array}$} & \multirow{4}{*}{$\begin{array}{l}40 \\
67 \\
35 \\
12\end{array}$} & \multirow{4}{*}{$\begin{array}{l}0.17(0.07-0.42) \\
0.35(0.16-0.76) \\
0.56(0.25-1.28) \\
1\end{array}$} & \multirow{3}{*}{ * } & \\
\hline & & & & & & \\
\hline & & & & & & \\
\hline & & & & & 1 & \\
\hline \multirow[t]{4}{*}{$\begin{array}{l}\begin{array}{l}\text { Level of } \\
\text { education }\end{array} \\
\end{array}$} & $\begin{array}{l}\text { College and } \\
\text { above }\end{array}$ & 56 & 37 & $2.1(1.21-3.62)$ & $2.2(1.16-4.16)$ & 0.016 \\
\hline & 2dry school & 22 & 32 & $0.95(0.5-1.82)$ & $*$ & \\
\hline & $\begin{array}{l}\text { Primary } \\
\text { school }\end{array}$ & 16 & 27 & $0.82(0.41-1.68)$ & $*$ & \\
\hline & $\begin{array}{l}\text { No formal } \\
\text { education }\end{array}$ & 52 & 72 & 1 & 1 & \\
\hline \multirow{2}{*}{$\begin{array}{l}\text { Ever been } \\
\text { pregnant }\end{array}$} & No & 53 & 31 & $2.52(1.5-4.2)$ & $3.06(1.63-5.76)$ & 0.001 \\
\hline & Yes & 93 & 137 & 1 & 1 & \\
\hline \multirow{2}{*}{$\begin{array}{l}\text { Got } \\
\text { counsellin } \\
\text { g service }\end{array}$} & No & 46 & 20 & $3.41(1.9-6.1)$ & $1.2(1.02-3.89)$ & 0.044 \\
\hline & Yes & 100 & 148 & 1 & 1 & \\
\hline \multirow{3}{*}{$\begin{array}{l}\text { Reason } \\
\text { for } \\
\text { choosing } \\
\text { method }\end{array}$} & Effectiveness & 26 & 20 & $1.89(1-3.6)$ & \multirow{3}{*}{$\begin{array}{l}* \\
*\end{array}$} & \\
\hline & No side effect & 28 & 14 & $2.91(1.46-5.83)$ & & \\
\hline & Long term & 92 & 134 & 1 & & \\
\hline \multirow{2}{*}{$\begin{array}{l}\text { Perceived } \\
\text { Satisfied }\end{array}$} & No & 74 & 23 & $6.48(3.75-11.19)$ & \multirow[t]{2}{*}{$4.86(2.66-8.91)$} & $<0.001$ \\
\hline & Yes & 72 & 145 & 1 & & \\
\hline \multirow{3}{*}{$\begin{array}{l}\text { Main } \\
\text { decider }\end{array}$} & Others & 57 & 28 & $2.97(1.71-5.18)$ & $*$ & \\
\hline & with husband & 26 & 48 & $0.79(0.45-1.41)$ & \multirow{2}{*}{$\begin{array}{l}* \\
1\end{array}$} & \\
\hline & Myself & 63 & 92 & 1 & & \\
\hline \multirow{2}{*}{$\begin{array}{l}\text { Ever } \\
\text { faced side } \\
\text { effects }\end{array}$} & Yes & 115 & 96 & $2.78(1.69-4.59)$ & $3.14(1.7-5.54)$ & $<0.001$ \\
\hline & No & 31 & 72 & 1 & $\mathbf{1}$ & \\
\hline
\end{tabular}

*= Not associated on forward stepwise (Wald) test 


\section{DiscuSSIONS}

In this study, the overall discontinuation rate of implanon was $46.5 \%(95 \% \mathrm{CI}=40.4 \%-52.3 \%)$ with the median duration of use 12 months. This rate is consistent with the study conducted in Australia where 47\%[17] of women using the implant discontinued within three years. However, it is higher than the study conducted in Nigeria, Egypt and Malaysia where the overall Implanon discontinuation rateswere $26.1 \%, 28 \%$ and $22.86 \%$ respectively $[7,18,19]$. Similarly, the rates of discontinuation at 6months, 12 months and 24 months were $10.5 \%, 23.9 \%$ and $38.2 \%$ which is higher than discontinuation rate observed in the above studies. The difference might be own to lack of counseling service during Implanon provision and follow-up service after method provision as $45.6 \%$ were not counseled on possible side effects in the current study. Effective counseling, close monitoring and follow up service enable women to cope with minor disorders.

Among the discontinuers, 33(22.6\%) discontinued within 6months, 75(51.4\%) within 12months, $120(82.2 \%)$ within 24 months and $146(100 \%)$ within 35 months. The rate of discontinuation at 6 month and one year were less than discontinuation rate observed in Ofla woreda, Tigray where the discontinuation were $53.8 \%$ and $97.4 \%$ at 6 months and one year respectively [16]. The difference could be due to the difference in the denominator since the denominator in the previous study was Implanon users in the last One andhalf years preceding study. However, the denominatorin this study was Implanon users in the last three years. The rate of discontinuation in 24 months washigher than discontinuation rate observed in Egypt where only 55\% discontinued before two years [19]. The difference could be due to follow up service provision after Implanon insertion in Egypt as 55\% of Implanon users had follow up service but no one was appointed for checkup in this study.

Unlike in other studies, this result showed that the odds of Implanon discontinuation among women who attended college and above level of education were twotimes higher than odds in those who have no formal education $[\mathrm{AOR}=2.2,95 \% \mathrm{CI}=1.16,4.16)]$ This might be due to different reasons. One reason might be due to the fact that early seeking care is common when there is some change (disturbance) among women who are more educated. Women who were more educated have the ability to early recognize any disturbance from normal physiology. Secondly, why the result is different from other studies could be due to difference in educational status of study participants. Studies conducted in Ofla district of Tigray region and Arsi zone of Oromia region, Ethiopia, were carried outin rural areas and majority of the participants (70\%) have no formal education, and the remaining $30 \%$ were primary and secondary school $[16,29]$. On the other hand, studies conducted in Nigeria, Malaysia, America and Australia indicatedthat themajority of the participants (66\%) were college and above while only a few of them were illiterate[6, 7, 18, 27]. However, the participants of this study have differenteducational levels which range from no formal education (39.5\%) to college and above levels $(29.6 \%)$.

The odds of Implanon discontinuation among women who had never been pregnant before Implanon use were three times higher than the odds in women who were pregnant at least once[AOR $=3.06$, $95 \% \mathrm{CI}=1.63,5.76, \mathrm{p}=0.001]$. This finding is supported by thestudy conducted in St. Louis County, America [22]. However, it isdifferent from the study conducted in Arsi zone, Oromia, Ethiopia where there is no association between ahistory of pregnancy and Implanon removal [29]. This might bedue to the difference in gravidity of study participants as $93 \%$ of participants in previous study had at least one pregnancy. Women who havenot been pregnant have more desire for future fertility compared to others.

The odds of Implanon discontinuation among women who did not get counseling service before insertion was 1.2 times higher than the odds in those who were counseled ( $\mathrm{AOR}=1.2,95 \% \mathrm{CI}=1.02$, $3.89, \mathrm{p}=0.044)$. This might bedue to the fact that women who were informedon the possible side effect of the method will tolerate minor changes(side effects), but those who were not informed will seek removal of the method.

The odds of Implanon discontinuation among women who perceived not satisfied with the service provided during Implanon insertion was 4.86 times higher than the odds in women who perceived satisfied (AOR=4.86, 95\% CI $=2.66,8.91, \mathrm{p}<0.001)$. This is similar with study conducted in Ofla woreda, Tigray, northern Ethiopia [16]. This might be because of women who were not interested in method choice and who were not well counseled will remove Implanon as $113(45.6 \%)$ of users were not counseled on side effects and Implanon use was decided by method providers for 73 (23.2\%) of users in this study. 
Moreover, the odds of Implanon discontinuation among women who experienced a side effect of the method was 3.07 times higher than the odds in women who did not experience side effects $(\mathrm{AOR}=3.07,95 \% \mathrm{CI}=1.7,5.54, \mathrm{p}<0.001)$. This is similar with the study conducted in ofla district, Tigray (16). This might be own to women's intolerance for minor side effects. Secondly,it could be own to unexpected change in menstrual bleeding due to the nature of the method.

\section{CONCLUSION}

In this study, Implanon discontinuation rate was high. Quality family planning service is essential to reduce discontinuation rate.

\section{Limitations}

The non-response rate was relatively high as study participants were not permanent residents in this study area. Moreover, the severity of side effect wasnot diagnosed.

\section{Author's Contribution}

MS conceived the study and was involved in the study design, reviewed the article,analysis, report writing and drafted the manuscript. ZM, MA \& HK participated in the study design, analysis and drafted the manuscript. All authors read and approved the final manuscript

\section{ACKNOWLEDGEMENT}

The authors acknowledge University of Gondar, Ethiopia for financial and material support. The authors appreciate study participants \& data collectors for their cooperation in providing all necessary information. We appreciate the comment of Mr. Amare Worke.

\section{REFERENCES}

[1] Mutihir JT, Nyango DD. Indications for removal of etonogestrel implant within two years of use in Jos, Nigeria. East Afr Med J. 2010 Nov;87(11)461-4. PubMed PMID: 23457809. Epub 2010/11/01. eng.

[2] Henry N, Schlueter M, Lowin J, Lekander I, Filonenko A, Trussell J, et al. Cost of unintended pregnancy in Norway: a role for long-acting reversible contraception. J Fam Plann Reprod Health Care. 2014 Dec 23. PubMed PMID: 25537792. Epub 2014/12/30. Eng.

[3] Tsui AO, McDonald-Mosley R, Burke AE. Family planning and the burden of unintended pregnancies. Epidemiol Rev. 2010 Apr;32(1):152-74. PubMed PMID: 20570955. Pubmed Central PMCID: PMC3115338. Epub 2010/06/24. eng.

[4] Bongaarts J, Cleland J, Townsend JW, Bertrand JT. Family planning programs for the 21st century: Rationale and design. 2012.

[5] Bradley S, Schwandt HM, Khan S. Levels trends and reasons for contraceptive discontinuation. 2008.

[6] Harvey C, Seib C, Lucke J. Continuation rates and reasons for removal among Implanon users accessing two family planning clinics in Queensland, Australia. Contraception. 2009 Dec;80(6):527-32. PubMed PMID: 19913146. Epub 2009/11/17. eng.

[7] Balogun O, Olaomo N, Adeniran A, Fawole A. Implanon sub-dermal implant: an emerging method of contraception in Ilorin, Nigeria. Journal of Medical and Biomedical Sciences. 2014;3(1):1-5.

[8] Mutihir J, Nyango D. One-year experience with implanon sub-dermal implants in Jos, Nigeria. Nigerian Journal of Clinical Practice. 2010;13(1).

[9] Ireland LD, Goyal V, Raker CA, Murray A, Allen RH. The effect of immediate postpartum compared to delayed postpartum and interval etonogestrel contraceptive implant insertion on removal rates for bleeding. Contraception. 2014 Sep;90(3):253-8. PubMed PMID: 24973904. Epub 2014/06/30. eng.

[10] Hoggart L, Newton V, Dickson J. Full Report. Understanding long-acting reversible contraception: an in-depth investigation into sub-dermal contraceptive implant removal amongst young women in London. A report for the London Sexual Health Commissioning Programme. 2013. 
[11] CSA M. Ethiopia mini Demographic and Health Survey 2011 Preliminary Report. Central Statistical Agency, Addis Ababa, Ethiopia. 2014.

[12] Meskele M, Mekonnen W. Factors affecting women's intention to use long acting and permanent contraceptive methods in Wolaita Zone, Southern Ethiopia: a cross-sectional study. BMC Womens Health. 2014;14:109. PubMed PMID: 25216640. Pubmed Central PMCID: PMC4237819. Epub 2014/09/14. eng.

[13] Asnake M, Solter C, Tilahun Y, Vespia M. Strengthening health systems to ensure equitable access to implant removal services in Ethiopia. 2013.

[14] Asnake M, Tilahun Y. Scaling up community-based service delivery of Implanon: the Integrated Family Health Programâ s experience training health extension workers. 2010.

[15] Asnake M, Henry EG, Tilahun Y, Oliveras E. Addressing unmet need for long-acting family planning in Ethiopia: uptake of single-rod progestogen contraceptive implants (Implanon) and characteristics of users. Int J Gynaecol Obstet. 2013 Nov;123 Suppl 1:e29-32. PubMed PMID: 24035007. Epub 2013/09/17. eng.

[16] Kalayu B. Early Discontinuation Rate of Implanon and its Associated Factors among Women who ever Used Implanon In 2012/2013 In Ofla Woreda, Tigray, Northern Ethiopia, 2014: Aau; 2014.

[17] Weisberg E, Bateson D, McGeechan K, Mohapatra L. A three-year comparative study of continuation rates, bleeding patterns and satisfaction in Australian women using a subdermal contraceptive implant or progestogen releasing-intrauterine system. The European Journal of Contraception \& Reproductive Health Care. 2014;19(1):5-14.

[18] Mastor A, Khaing SL, Omar SZ. Users' perspectives on Implanon in Malaysia, a multicultural Asian country. Open Access Journal of Contraception. 2011:79-84.

[19] Said MA-RM, Cairo U. Implanon Use Pattern among Ministry of Health and Population Clients 2008-2012.Faculty of Medicine,Cairo 2012 December,2012.

[20] Eva G, Ngo TD. MSI Mobile Outreach Services: Retrospective evaluations from Ethiopia, Myanmar, Pakistan, Sierra Leone and VietNam. London: Marie Stopes International. 2010.

[21] Hardee K, Harris S, Rodriguez M, Kumar J, Bakamjian L, Newman K, et al. Achieving the Goal of the London Summit on Family Planning By Adhering to Voluntary, Rights-Based Family Planning: What Can We Learn from Past Experiences with Coercion?

[22] Madden T, Eisenberg DL, Zhao Q, Buckel C, Secura GM, Peipert JF. Continuation of the etonogestrel implant in women undergoing immediate postabortion placement. Obstet Gynecol. 2012 Nov;120(5):1053-9. PubMed PMID: 23090522. Pubmed Central PMCID: PMC3711380. Epub 2012/10/24. eng.

[23] Rosenstock JR, Peipert JF, Madden T, Zhao Q, Secura GM. Continuation of reversible contraception in teenagers and young women. Obstet Gynecol. 2012 Dec;120(6):1298-305. PubMed PMID: 23168753. Pubmed Central PMCID: PMC4037699. Epub 2012/11/22. eng.

[24] Jacobstein R, Polis CB. Progestin-only contraception: injectables and implants. Best Pract Res Clin Obstet Gynaecol. 2014 Aug;28(6):795-806. PubMed PMID: 24996766. Epub 2014/07/06. eng.

[25] Duvan Cİ, Gözdemir E, Kaygusuz İ, Kamalak Z, Turhan NÖ. Etonogestrel contraceptive implant (Implanon): Analysis of patient compliance and adverse effects in the breastfeeding period. Journal of the Turkish German Gynecological Association. 2010;11(3):141.

[26] O'Neil-Callahan M, Peipert JF, Zhao Q, Madden T, Secura G. Twenty-four-month continuation of reversible contraception. Obstet Gynecol. 2013 Nov;122(5):1083-91. PubMed PMID: 24104781. Pubmed Central PMCID: PMC4012225. Epub 2013/10/10. eng.

[27] Peipert JF, Zhao Q, Allsworth JE, Petrosky E, Madden T, Eisenberg D, et al. Continuation and satisfaction of reversible contraception. Obstet Gynecol. 2011 May;117(5):1105-13. PubMed PMID: 21508749. Pubmed Central PMCID: PMC3548669. Epub 2011/04/22. eng.

[28] Grunloh DS, Casner T, Secura GM, Peipert JF, Madden T. Characteristics associated with discontinuation of long-acting reversible contraception within the first 6 months of use. Obstet Gynecol. 2013 Dec;122(6):1214-21. PubMed PMID: 24201685. Pubmed Central PMCID: PMC4051392. Epub 2013/11/10. eng. 
Implanon Discontinuation Rate and Associated Factors among Women who ever Used Implanon in the Last Three Years in Debre Markos Town, Northwest Ethiopia, 2016, Cross Sectional Study

[29] Burusie A. Reasons for Premature Removal of Implanon among Users in Arsi Zone, Oromia Region, Ethiopia, 2013. Reproductive System \& Sexual Disorders. 2015;2015.

[30] Halpern V, Lopez LM, Grimes DA, Stockton LL, Gallo MF. Strategies to improve adherence and acceptability of hormonal methods of contraception. status and date: New search for studies and content updated (no change to conclusions), published in. 2013 (10).

[31] Wellisch LD, Chor J. LARC First: What the General Pediatrician Needs to Know about IUDs and Contraceptive Implants. Pediatric annals. 2013;42(9):380-3.

[32] Rowlands S, Searle S, Rowlands S, Searle S. Contraceptive implants: current perspectives. Clinical, Cosmetic and Investigational Dentistry. 2014;6:45-56 